\title{
Why We Need Hands-On Engineering Education*
}

\section{Arnold D. Kerr and R. Byron Pipes}

Worried about the declining competitive position of U.S. industry, many people are pointing to a crisis in engineering education. The majority see faculty shortages and outdated laboratories as the most critical factors. Therefore, they usually propose allocating more government funds to universities for both research and up-to-date equipment, on the assumption that more funds will attract more students to doctoral programs, which in turn will provide more engineering faculty.

These "solutions," however, sidestep the real crisis in engineering education - namely, its emphasis on engineering science at the expense of engineering design. Engineers design products, structures, and systems, whereas engineering scientists develop the basic knowledge that engineers need. But that difference has become obscured in modern engineering education. As a 1986 National Research Council (NRC) review of engineering-college catalogs from the past 30 years disclosed, an "unmistakable trend of increasing science and engineering science content" has emerged in the curricula. Nam P. Suh, assistant director of the National Science Foundation (NSF), says in another 1986 NRC report that "while analysis in engineering science is an important facet of engineering, it is clear that we have neglected synthesisoriented skills such as design."

As a result, potentially creative designers are either unchallenged or discouraged by the current curricula. Today the top engineering students are

*Reprinted with permission from Technology Review, copyright 1987. the top analysts, not the top designers.

We believe that the emphasis of engineering science over design has contributed significantly to the decline of the nation's industrial base. Clearly many factors are at work - such as management's short-term financial objectives and labor practices that inhibit productivity - but the lack of design capability among U.S. engineers is predominant. According to yet another 1986 NRC report, U.S. engineering graduates no longer have the feel they once had for creating complete, functioning systems.

For example, the majority of graduating mechanical engineers cannot design a combustion engine. They may have studied the strengths and properties of various materials or the way gases flow and react in turbines, but they have not necessarily learned how the parts of an engine are designed, manufactured, and assembled - or even how the components work.

\section{Design: From Graphics to Economics}

Design has fallen so low in the order of educational priorities that many engineers - especially young ones and students - do not understand its meaning. The Accreditation Board for Engineering and Technology defines engineering design as "the process of devising a system, component, or process to meet desired needs." Essential to developing competitive products, design is the central activity of the engineering profession. In the course of designing, the engineer creates by relying on everything from intuition and graphics to science and economics.
Consider the tasks of the civil engineer who bids on designing a highway bridge over a wide river. The engineer must first determine possible bridge shapes based not only on his or her knowledge of mathematical analysis of structures, but also on such information as long-range traffic forecasts and the area's terrain. For instance, will delivery of the bridge materials involve travel along mountainous roads with tightly curving tunnels, prohibiting the use of long prefabricated spans? Will the river ice up in winter, making a girder bridge with many piers undesirable?

The engineer must next consider details such as the dimensions of individual bridge members, the design of the bridge piers and abutments, and the appropriate construction method. Again, he or she must rely on intuition and experience as well as a knowledge of science: For instance, if the soil at the river's edge is soft clay, the engineer must know that abutments will have to be placed on piles driven into firmer soil. If a suspension bridge is called for the engineer will have to recognize that suspension cables are too heavy to weave off site. So he or she will have to design a special platform for weaving the cables over the construction site. Then the engineer must estimate the total cost by conducting an economic analysis, which requires an understanding of the costs of materials and construction methods. Throughout this process, the engineer also has to recognize that aesthetics, cost, and local politics may determine whether his or her design will be chosen.

Similarly, the mechanical engineer's understanding of design know-how including his or her ingenuity and knowledge of marketing needs makes the difference between an innovative and mediocre product, and the number of possible sales. For example, the Cuisinart food processor involves no new technology, but it is a world apart from the blender, its predecessor. While the blender with its small fixed blade can only mix and puree, the food processor can chop, shred, puree, and even knead dough with a variety of large exchangeable blades. The development of the versatile food processor required no novel theories or analyses, just creative design.

\section{The Waning of Engineering}

\section{Design Education}

Before World War II U.S. engineering education was pragmatic. A typical engineering curriculum included not 
only physics, mathematics, and other sciences, but courses in drafting, design, construction or production methods, and economic analysis. The tone was of a professional technical school. Most graduates expected to enter industry after earning their bachelor's degree. And those who joined the faculty typically did so after a successful career in industry. Few professors held a doctoral degree; rather, they taught from a broad base of engineering experience.

After World War II the situation changed dramatically. The great wartime advances in aeronautics, electronics, and nuclear technology had a strong effect on the attitudes of the public and on the U.S. government. Engineering schools introduced more mathematics and science in the curricula, along with a greater emphasis on graduate study. Expanding or newly established government and industry research laboratories, such as the naval research labs, the U.S. Army Waterways Experiment Station, Bell Labs, and IBM Research Centers, afforded a ready market for science-oriented engineers, especially those with advanced degrees.

To make room in the undergraduate curricula for more science and mathematics, courses dealing with engineering practice were de-emphasized or dropped. They were least in step with the new trend. Many design programs deteriorated rapidly. An alternative would have been to add engineeringscience departments while preserving the design-oriented programs.

Perceiving national interests to be at stake in the advancement of science and technology, the federal government indirectly financed the curriculum change by supporting engineeringscience research at universities. Part of this support came through grants from the NSF, founded in 1950 . From the late 1950 s on, the greatest impetus for research came from space exploration and defense. Faced with the challenges of space flight and the manned landing on the moon, NASA initiated a broad program of funding university research. Other sources of support were created by the armed forces through their research offices: the Air Force Office of Scientific Research, the Office of Naval Research, the Army Research Office, and later the Defense Advanced Research Projects Agency. The practice of funding research at universities also spread to other federal agencies, such as the Department of Transportation and the Department of Energy.

The simple availability of such funds led university administrators and faculty to seek the grants. They were motivated as well by a desire to enhance the national reputation of their institutions. An essential step in this direction was to appoint recent recipients of doctoral degrees to faculty positions. These individuals were good candidates for grants because of their research training and their familiarity with the latest scientific advances.

The movement toward engineering science has become self-perpetuating. Research funds provide support for graduate students, who after graduation constitute the pool of young faculty members needed to continue expanding the research programs.

Incoming engineering faculty typically have little or no experience in design, yet they are the ones frequently expected to teach design courses. Often considering the classes a burden, these professors usually adhere to a standard design text and are unable to enrich courses through personal knowledge. To secure tenure, they generally do research in the engineering sciences, for which grants are available and results can readily be published.

\section{The health of U.S. industry depends partly on developing a pragmatic approach to engineering education.}

The situation is growing worse as design professors with actual experience retire. Should the number and quality of design courses continue to drop, the engineering programs at U.S. universities will become, in our view, pre-engineering programs at best, insufficient to prepare students for the effective practice of engineering.

The primary force deterring this development is the Accreditation Board for Engineering and Technology (ABET). Since $1970 \mathrm{ABET}$ has responded to industry's urgings by calling for a minimum design content in the engineering curricula. The board requires 12.5 percent of the total credits, or 16 semester credit hours, to be design courses. Almost all universities have attempted to partially meet those requirements by claiming design credits within some nondesign courses. For example, a university may try to claim that one-third of the credit hours in a structural analysis course - which concerns the calcula- tions of beams, frames, and arches relates to design. ABET accreditation teams, however, frequently dispute faculty evaluations of what constitutes design. Currently, some organizations that belong to $\mathrm{ABET}$ are attempting to reduce its minimal design requirements. Actual design experience among those teaching the design courses has not even been an ABET condition.

\section{The Harm to U.S. Industry}

Employers report that new engineering graduates at all levels are often unable to contribute to product design teams and require extensive on-the-job training. Many of them "seem to have a total misunderstanding of the overall design process," wrote Edward G. Naumann last year in Mechanical Engineering. Naumann, a structural design manager for LTV Vought Aero Products Division, described a senior design project sponsored by LTV at a major university. The students were asked to design a rectangular exterior panel for an aircraft's fuselage, based on load requirements that Naumann prescribed. The final report contained extensive numerical analysis, but no drawings to specify the panel's proper dimensions. In fact, the students had not designed the panel.

"The vast majority of newly graduated engineers are trained for analysis positions and are rarely exposed to design engineering practices," says Frank M. Manders, chairman of the design engineering technical committee for the American Institute of Aeronautics and Astronautics.

In large corporations, young engineers can obtain design skills and knowledge by working in design groups. But this practice tends to be inadequate. The new engineer who learns from a group of experienced designers steeped in one company's approach and style gains at best a narrow view of design. Another problem is that some industries such as the machine-tool and the automotive- and electronic-supply businesses are mostly comprised of small companies. While innovative design is key to their survival, they cannot afford the same on-the-job design training as large corporations.

New tools such as computer-aided design and expert systems cannot be expected, at least in the near future, to compensate for the lack of a thorough design education. These powerful aids can sharpen a design and test a large variety of options quickly. But much of engineering is based on techniques that 
involve intuition, experience, and common sense. Until artificial intelligence can capture the full range of such qualities, computer-aided methods will serve primarily as an adjunct to engineering creativity, not a substitute.

U.S. engineering graduates' lack of exposure to design and manufacturing partly explains the country's disadvantage in developing well-designed and well-manufactured products. We find it telling that General Motors relied on German engineering to design the 1988 Pontiac LeMans. (The company even advertises that fact!) Or consider the way the president of one American company located a contractor to design a videocassette recorder - a technology based on U.S. engineering research. He went to several well-known American audiovisual firms but could find none that was qualified or willing to undertake the task. The knowledge required to design mechanical systems of this type seems rare among American engineers. Reluctantly, the executive went to Japan, where he quickly found the necessary expertise.

\section{How Other Nations Train Engineers}

It is useful to examine how Germany and Japan structure engineering education. In West Germany, technical university students primarily take mathematics, physics, chemistry, and "technical" - or applied - mechanics during their first two years. In the two to three remaining years the curriculum emphasizes design courses taught by professors who are generally outstanding engineers from industry.

In Japan, undergraduate engineering curricula are much more like those in the United States. Design is not emphasized, especially at the prestigious national universities. The difference comes after graduation. The Japanese company - at which an employee may stay for his or her entire careerprovides its engineers with intensive design training for as long as two years, both in the classroom and on the shop floor. In addition, design teams often oversee a product all the way through production - a practice that greatly enhances an engineer's insight into practical design requirements.

This approach works well in Japan, where many engineers do not switch firms. But with a frequent turnover of engineers, most U.S. companies are unwilling to make such a heavy investment in training. In the United States the universities must be the source of engineering design education.

\section{Solving the Problem}

Leaders in U.S. industry, government, and academia are starting to recognize that the deemphasis of design is damaging the country's engineering enterprise. Perhaps the clearest acknowledgment of the problem has come from the NSF. Its recently initiated program of Engineering Research Centers, located at universities, recognizes that to be more competitive internationally, U.S. engineers must improve their ability to design. For instance, Carnegie Mellon University recently won a $\$ 14.9$ million grant through this program to undertake a major expansion of its design center, which it started in 1974. To date, NSF has committed more than $\$ 200$ million to the engineering centers program.

Some universities have been taking action as well. Most schools are offering senior engineering students "capstone" courses that consist of designing a

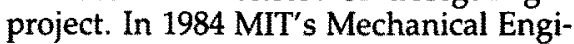
neering Department formalized its design program by establishing the Martin Center for Engineering Design, where students both design and conduct research on design methods. MIT and other schools are also considering emphasizing design through mechanisms such as new faculty chairs and student fellowships.

\section{Computer-aided design cannot substitute for a thorough design education.}

These programs, pronouncements, and intentions are positive signs. Taken alone, however, they cannot make up for the lack of design expertise among graduating engineers. All engineering schools need to systematically change their programs to restore the balance between engineering science and design. This should be done through faculty appointments, since the nature of the curricula and the quality of courses depends largely on the composition of the faculty in a given department.

The College of Engineering at the University of Delaware is planning to do just that. The school's approach consists of two phases. The starting point is the implementation of the ABET requirements in spirit as well as in letter. The first phase retains the ABETapproved curricula and seeks to ensure that qualified faculty are available to teach the design courses. In addition, the engineering departments are beginning to require that senior undergraduates complete a capstone design course. Toward the end of the senior year, each student must submit a report containing a description of the project, background information, drawings, analyses, and the proposed method of construction or manufacture. Students may design anything from turbines to bridges to computers. Each project will be supervised by a design professor and assistants.

The second phase will extend design activities into the graduate programs and establish design-oriented master's degrees. Unlike current MS programs that emphasize engineering sciences, the new degrees will stress design methods, case studies of successful designs, examinations of engineering failures, and new tools such as computer-aided design and manufacturing and artificial intelligence.

The existing PhD programs are research degrees, and so their emphasis on science and mathematics is appropriate. However, like the MS degrees currently offered, these awards should be termed engineering-science degrees to distinguish them from design-oriented engineering programs.

To help carry out this program, the university will appoint appropriate design faculty members as needed. Increases will be gradual, with job openings filled as required. The desirable ratio will depend on the department. For example, as part of the first phase in civil and mechanical engineering, the goal would be one design professor for every four in the engineering sciences. For the second phase, a ratio of one design professor to two or three in engineering sciences seems appropriate.

A candidate for a full professorship in design would be an outstanding designer from industry with 20 to 30 years of experience. A doctoral degree should not be required, although knowledge of the latest technical developments should. A design professor should follow design trends in industry and continue to develop design expertise.

Some current faculty members may argue that qualified engineers are not likely to leave industry for often lowerpaying academic positions. On the contrary, many senior engineers in industry may find a professorship appealing, as it would give them time to think and experiment and the opportunity to summarize design experiences accumulated over decades. These are advantages 
that, for some, may be worth a salary cut. And to make a faculty position more attractive, tenure could be granted at the start of full-time teaching.

Those who oppose a change in curricula also argue that the design experience of professors who come from industry may quickly become obsolete. But while designs for many structures, mechanical devices, and systems have been changing rapidly, basic design knowledge changes very little. This element of a student's education will outlast training acquired on the job.

An additional benefit to appointing experienced engineers to design professorships is that they will ease the faculty shortage in engineering. The pool of potential applicants for faculty positions will increase enormously if senior industry designers are included.

Many recent federal programs that are funding $R \& D$ to improve the competitiveness of U.S. industry are at this point more likely to help our competitors. The programs' results will be accessible to other countries that have design engineers ready to put them into practice.

\section{Many industrial engineers could apply their decades of experience in teaching.}

To help our industries, the government should modify the funding processes that created the present situation in engineering education. Agencies such as the NSF, NASA, Air Force Office of Scientific Research, Office of Naval Research, and Army Research Office should allocate a small fraction of their research grants to qualified engineering-design professors who want to develop novel designs or write practical design textbooks. If these agencies can convince the universities that they will continue funding these types of design research, the universities will likely begin appointing experienced design engineers as professors.

The steps we suggest for universities and federal agencies are not radical. Yet, if adopted, they will create a balance between the engineering specialties that in the long run will contribute substantially toward improving the competitiveness of U.S. industries.

Arnold $D$. Kerr is a professor of civil engineering at the University of Delaware's College of Engineering. R. Byron Pipes is dean of that college and a member of the National Academy of Engineering.

\section{Proceedings from Japan International Conferences to be Published by the Materials Research Society}

The Materials Research Society will publish the proceedings of two recent international materials conferences held in Tokyo. Japan. The Proceedings of the MRS International Meeting on Advanced Materials, held May 30-June 3, 1988, will be published in 14 multi-topic and single-topic volumes. The Proceedings of the ISAP-MRS International Conference on Electronic Materials, held June 13-15, 1988, will be published in one comprehensive volume.

\section{Proceedings of the MRS International Meeting on Advanced Materials}

Vol. 1: Symposium N-Biomaterials

Symposium $\mathrm{P}$-lonic Polymers

Symposium Q-Ordered Polymers for

High Temperature

Materials

Vol. 2: Symposium I-Hydrogen-Absorbing Materials

Symposium O-Catalytic Materials

Vol. 3: Symposium B-Rapid Quenching Symposium C-Powder Preparation

Vol. 4: Symposium A-Composites

Symposium G-Corrosion/Coating of Advanced Materials

Vol. 5: Symposium J-Structural Ceramics Symposium M-Fracture Mechanics

Vol. 6: Symposium D-Superconductivity
Vol. 7: Symposium E-Superplasticity
Vol. 8: Symposium F-Joints of Metals and Ceramics
Vol. 9: Symposium H-Shape Memory Materials
Vol. 10: Symposium K-Multilayers
Vol. 11: Symposium L-Microstructure-Property Relationships in Magnetic Materials
Vol. 12: Symposium R-Photoresponsive Materials
Vol. 13: Symposium S-Advanced Cements and Chemically Bonded Ceramics

Vol. 14: Symposium T-Biosensors

\section{Proceedings of the JSAP-MRS International Conference on Electronic Materials}

For prices and ordering information, contact: Publications Department, Materials Research Society. 9800 McKnight Road. Suite 327. Pittsburgh. PA 15237: telephone (412) 367-3012: fax (412) 367-4373. 


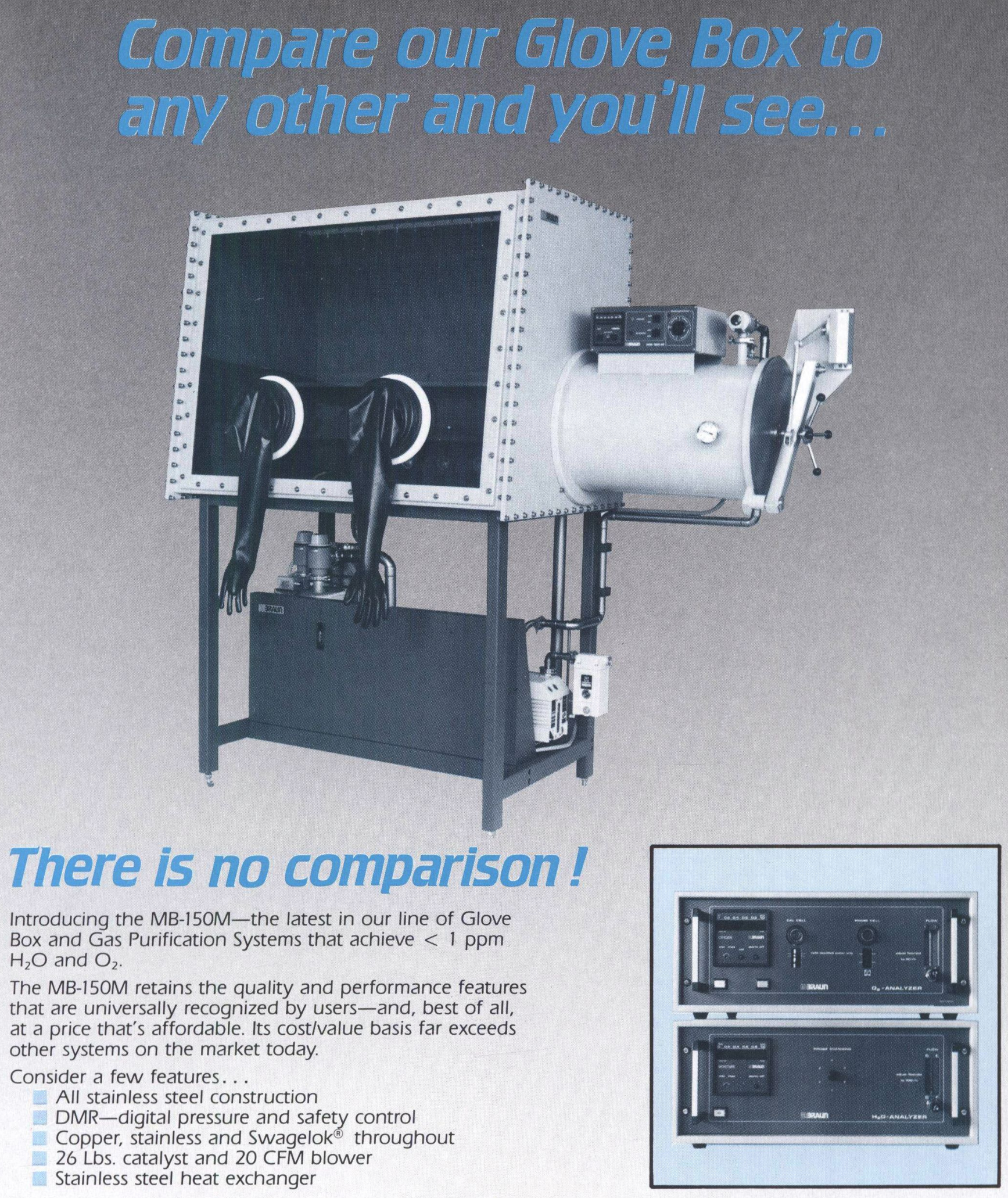

The design criteria for this system stresses modularity and expansion. Our new catalog describes the many options that can easily be added to the basic system. The MB-150M can also be expanded to a two box system.

For more detailed specifications, please write or call. Systems are available for demonstration in our lab.

INNOVATIVE. . . that's our first name !

Above: Our analyzers have been specifically designed for the measurement of oxygen and moisture in inert gases. We offer both analog and digital (shown) readouts. The analyzers are supplied complete with batching pumps and are ready to run. They are easily adapted to existing systems. All analyzers include chart recorder outputs, trigger alarms, automatic range selection and Swagelok ${ }^{\circledR}$ connectors.

\section{Q. innountive}

205 Willow St., South Hamilton, MA 01982 Phone: (508) 468-3543 Fax: (508) 468-1101 


\section{PHI-ATOMIKA - Defining New Standards in SIMS Performance!}

\section{Introducing the \\ Model 6500...}

Setting the "Standard of

Excellence"' in High Performance

SIMS Instrumentation

* Matrix gate "checkerboard" for simultaneous depth profiling/ion imaging. Allows data verification, interpretation and optimization after measurement.

* High throughput....with quick sample alignment, high depth profile speed, and storage of parameter sets for computer controlled "unattended" operation.

* Four types of programmable ion beam scanning... $X-Y$ raster scan (256X256), $X$ and $Y$ line scans, and unique spiral scan.

* State-of-the-art UHV pumping system.

* Simultaneous SIMS/AES available.

* Elaborate user-oriented data processing.

\section{Complemented by the} Model 6300...

A Cost-Effective System Offering

Superior Sensitivity with

Automated Analysis.

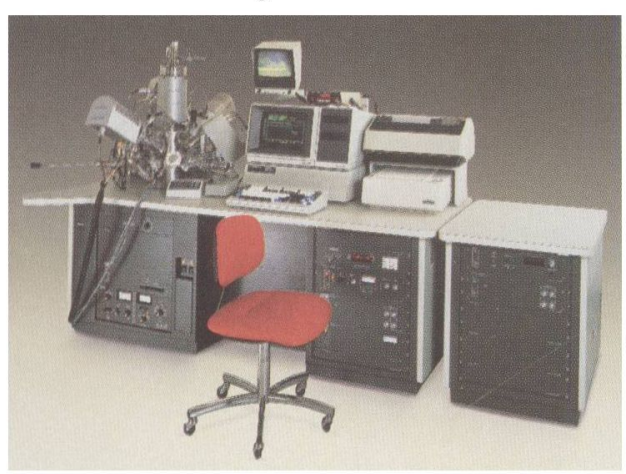

PHI-ATOMIKA...SIMS for sensitivity, automation, answers.

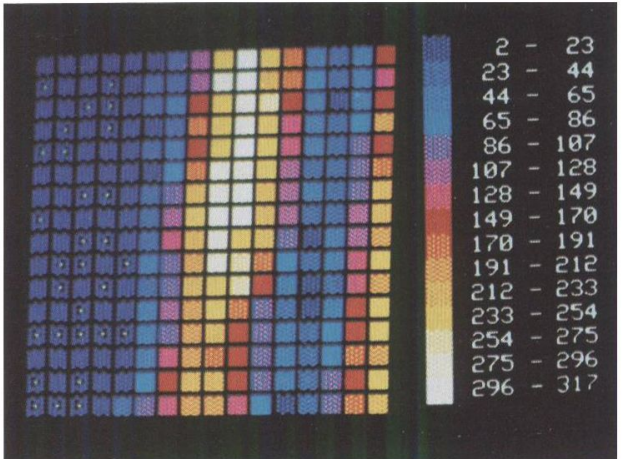

Unique checkerboard shows the spatially resolved distribution of the selected chemical element for one data point in the depth profile. Different secondary ion energy ranges are shown in different colors.
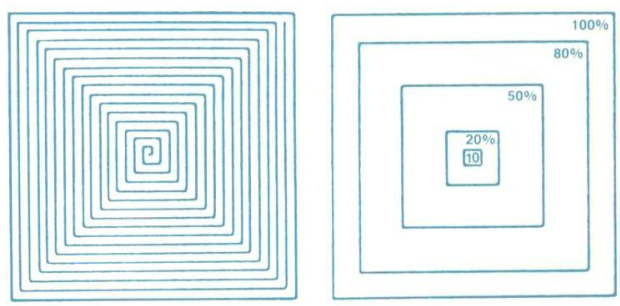

Primary ion beam rastered in spiral scan mode, enabling optimum gate size to be selected after depth profile measurement.

* Ultra pure dual ion guns for optimum detection limits.

* Fully automated control allows unattended multi-sample analysis.

* Variable angle bombardment to optimize angle of impact during analysis.

For complete information and specs: Perkin-Elmer, Physical Electronics Division 6509 Flying Cloud Drive

Eden Prairie, MN 55344 USA

(612) 828-6300 TIx: 290407

ATOMIKA Technische Physik GmbH Postfach 450135

D-8000 München 45

(089) 3155556 Tlx: 897389 